\title{
AN OVERVIEW OF OCCUPATIONAL VOICE DISORDERS IN POLAND
}

\section{EWA NIEBUDEK-BOGUSZ and MARIOLA ŚLIWIŃSKA-KOWALSKA}

The Nofer Institute of Occupational Medicine, Łódź, Poland

Department of Audiology and Phoniatrics

\begin{abstract}
Occupational voice disorders make the most frequently certified category of occupational diseases in Poland, making up approximately $20 \%$ of all cases. This study presents the current knowledge of the etiopathogenesis of occupational voice disorders. It stresses the importance of the evaluation of vocal loading by means of objective measurements. Furthermore, this study discusses the medico-legal aspects of the procedure of certifying occupational voice disorders in Poland. The paper also describes the preventive programs addressed particularly to teachers, including multidisciplinary and holistic management of occupational dysphonia. Their role in the improvement of occupational safety and health (OSH) arrangement for vocally demanding professions is emphasized.
\end{abstract}

Key words:

Occupational voice disorders, Vocal loading, Occupation-related larynx lesions, Diagnosing, Certification, Prevention

\section{INTRODUCTION}

During the last decades considerable changes have taken place in the occupational safety and health (OSH) strategies in the member states of the European Union. The dynamic transformations in different sectors of the labor market trigger a lot of trends implying the need to extend the $\mathrm{OSH}$ thinking to new domains. This situation concerns also voice disorders, because in the information age, voice has assumed an important role in occupational activities. Due to this fact, voice problems have an increasing impact on the career of numerous professional voice users as well on the reduction of profits of their employers. The UK data indicate that more than five million workers are routinely affected by voice impairments at an annual cost of approx. 200 million pounds [1]. Therefore, occupational voice disorders are a multifold problem, involving social, economic and public health aspects. It is necessary to stress that in Poland this problem is particularly important, because occupational voice disorder is both a medical and a legal term, which entitles a patient (with a certified case of an occupational voice disorder) to either a single financial compensation, or a pension, if partial work disability is confirmed [2].

Some studies have revealed that voice problems are more frequent among teachers than in other occupations [3,4]. It is a significant fact not only in Poland but also in other countries. For example, according to the American data, at least 1 in 3 teachers claims that teaching has a detrimental effect on their voice, and sometimes even forces them to change the profession [5]. A Polish randomized study addressing the problem of the prevalence of voice disorders in teachers demonstrated that the prevalence of self-reported symptoms and clinical signs of dysphonia was approx. 3 times higher in the teachers than in the controls

Received: October 25, 2012. Accepted: September 13, 2013.

Corresponding author: E. Niebudek-Bogusz, Department of Audiology and Phoniatrics, Nofer Institute of Occupational Medicine, św. Teresy 8, 91-348 Łódź, Poland (e-mail: ebogusz@imp.lodz.pl). 
(32.7\% in the teachers vs. $9.6 \%$ in the controls) [6]. Thus, the recognition of potential vocal health risk has been substantiated, since chronic voice problems frequently cause a serious communication handicap for professional voice users.

\section{ETIOPATHOLOGY OF OCCUPATIONAL VOICE DISORDERS}

The factors which affect the voice organ include: chronic vocal loading, environmental factors and psychoemotional factors $[7,8]$. Prolonged voice effort, often in the presence of background noise, has been implicated as a serious risk factor for vocal dysfunction, particularly in teachers. Another important issue in the pathogenesis of occupational dysphonia in this professional group is the use of incorrect techniques of voice production causing improper compensation of heavy vocal loading [9]. Furthermore, classroom environment with improper acoustic and reverberation parameters may increase vocal effort of the speaker $[10,11]$. Also, a poor microclimate comprising dust or even organic pollution, poor humidity, and exposure to fluctuations of temperature may affect the condition of the larynx mucosa in professional speakers and thus enhance voice problems $[12,13]$. Other factors which may also irritate the larynx mucosa include allergy and laryngo-pharyngeal reflux [14]. Recently, some authors have emphasized that psychosocial factors play an important role in handling the demands of a professional voice user and are related to voice disorders. Several studies have proven that voicing with adverse psychoemotional attitude can decrease vocal endurance $[15,16]$. Some stress the role of the biopsychosocial impact of voice disorders in relation to coping strategies in professional voice users [17].

As demonstrated in a Polish cross-sectional study, the main risk factors for developing occupational dysphonia are lifetime vocal loading, incorrect techniques of voice production, and psychological predisposition [6]. The negative vocal adaptation in the case of chronic vocal overload may induce muscle tension in the area of the pharynx, larynx and neck, affecting body posture and the breathing pathway, which, in consequence, results in inappropriate voice production and in the development of voice disorders. Koufman presented the vocal abuse syndromes in professional voice users as common primary muscle tension patterns (MTPs) [18], which are responsible for phonation with imbalanced or excessive muscular forces. These patterns bring about chronic dysphonia, which is characterized by vocal fatigue and reduced voice capacity. Professionally determined voice disorders are more frequently of functional (non-organic) origin than of organic origin [19]. However, non-treated long-lasting functional dysphonia may lead to an irreversible worsening of voice efficiency. Furthermore, this condition may induce organic lesions of the larynx. The most common laryngeal manifestations of vocal hyperfunction include: vocal nodules, hypertrophy of the vocal folds margin, vascular lesions of the glottis, contact ulcers, and asthenia of internal larynx muscles contributing to glottal insufficiency [12,20,21].

\section{VOCAL LOADING FROM THE OCCUPATIONAL PERSPECTIVE}

Recently, several authors have emphasized the importance of thorough studies concerning the effects of vocal loading on the vocal function in the aspects of occupational dysphonia [22-24]. Vilkman stressed that load-related physiological changes may play a role in the occupational risk [25]. That is why the objective evaluation of the effects of vocal loading seems particularly valuable.

One of the methods for estimating vocal load effects is the acoustic analysis with a vocal loading test. This method consists in reading aloud a text for 30 mins at the level of background (white) noise of $85 \mathrm{dBSPL}$ (decibels sound pressure level). The acoustic analysis and laryngovideostroboscopy are performed before and after the vocal 
loading. A comparison of the pre- and post-test acoustic and videostroboscopic parameters may enable clinicians to detect even early stages of occupational dysphonia. A Polish study proved that after vocal loading, some acoustic parameters (jitter, shimmer, and NHR) deteriorated in patients with irreversible occupational voice disorders [26]. These changes (a positive vocal loading test) are often accompanied by detrimental load-related effects on the videostroboscopic parameters.

Another study demonstrated that a negative vocal loading test was noted in subjects with a well-functioning voice or with slight, reversible voice disorders [27]. These observations could be explainable by a vocal warm-up, which is an effect of a positive compensation of the vocal load in subjects with sufficient vocal capacity. The vocal warmup effect is the result of proper voice adaptation, enabling easier phonation in the case of extreme vocal effort.

Therefore, the simple vocal loading test can be used for objective voice examinations in vocally demanding professions and for the assessment of "voice fitness for duty". It can be applied as a tool not only for estimating the degree of dysphonia, but also for evaluating the progress of a voice therapy [28]. Other valuable devices of vocal load monitoring in professional speakers are individual dosimeters collecting acoustic data of voice in the workplace; e.g. APM (Ambulatory Phonation Monitor) or Vox$\log [29,30]$. However, these measurements have not been commonly used yet because of the costs of the equipment. On the other hand, it is important to stress that voice is something more than a purely mechanical or acoustic phenomenon. According to Brodnitz, the voice is a mirror of personality, a carrier of moods and emotions [cited 20]. Therefore, even the most advanced objective measurements do not make it possible to assess the level of handicap of subjects suffering from voice disorders. Furthermore, in reference to the WHO multidimensional concept of health as physical, mental and social well-being, it is important to measure how much one's quality of life has deteriorated due to dysphonia [31]. Dysphonia is defined as an array of self-reported symptoms and clinically observed signs of pathological voicing. This definition reflects a large degree of subjectivity in the identification of different complaints, e.g. vocal fatigue, one of the most common complaints in professional speakers [19]. Therefore, a subjective evaluation of voice handicap ought to be taken into account particularly among professional voice users.

One of the most popular tools of self-assessment that has been designed to evaluate the quality of life specific to dysphonia is the Voice Handicap Index [32]. An international project has demonstrated that the VHI results obtained from studies conducted in various countries are comparable [33]. Other methods of voice self-assessment include the following: V-RQOL (Voice-Related Quality of Life), VOS (Voice Outcome Survey), and VoiSS (Voice Symptom Scale) [15]. Some authors, however, have also developed questionnaires which evaluate negative sensations related specifically to vocal loading [24]. Laukkanen et al. stressed that voice evaluation should accommodate the possible individual susceptibility to vocal fatigue [34]. At this point, it seems quite obvious that further research in this field is necessary.

\section{MEDICO-LEGAL ASPECTS OF OCCUPATIONAL VOICE DISORDERS IN POLAND}

Although the total number of certified occupational voice disorders dropped dramatically from over 2400 cases in the year 2000 to 228 cases in the year 2011 (Figure 1) [35], this disease entity is among the most frequently recognized occupational diseases in the last decade. The peak was at the turn of the 21st century, when in 1999 and in 2000 the newly registered occupational voice disorders constituted about $34 \%$ of all certified occupational diseases (Figure 2). This disease is certified mainly among teachers; the representatives of other professions (workers of 
call centers, singers, sports coaches) constitute fewer than $0.5 \%$ of the total. The downward trend observed in the last years seems to be the result of:

- socio-economic changes in the teaching professions (which encourage teachers to extend their retirement age rather than take early retirement and try to obtain compensation in the form of occupational disability pension);

- new legal regulations, introduced twice in the last decade (in 2002 and in 2009), on diagnosing occupational voice disorders, specifying both the type and extent of laryngeal pathologies;

- improvement in the methods of voice assessment during the certification procedure, including functional diagnostics of the larynx;

- implementation of numerous preventive programs for teachers and development of medical centers providing treatment of occupational voice disorders.

The main principles underlying the procedure of certifying occupational voice disorders are: confirming essential exposure to vocal loading, diagnosing typical occupationrelated lesions of the vocal folds, proving their irreversibility and confirming the relationship between the exposure and larynx pathology. The objective evaluation of vocal endurance in professional voice users may, to some extent, be problematic. The instrumental methods of assessment of voice disorders include videolaryngostroboscopy, glottography, kymography, aerodynamic and acoustic

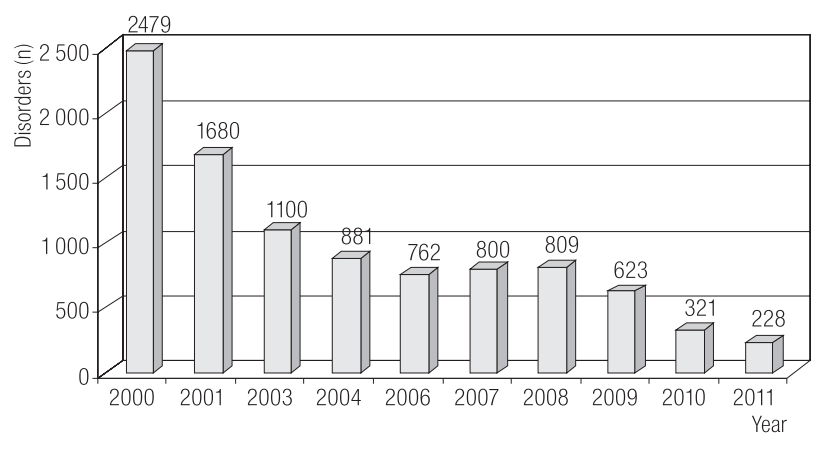

Fig. 1. Occupational voice disorders in Poland in the years 2000-2011

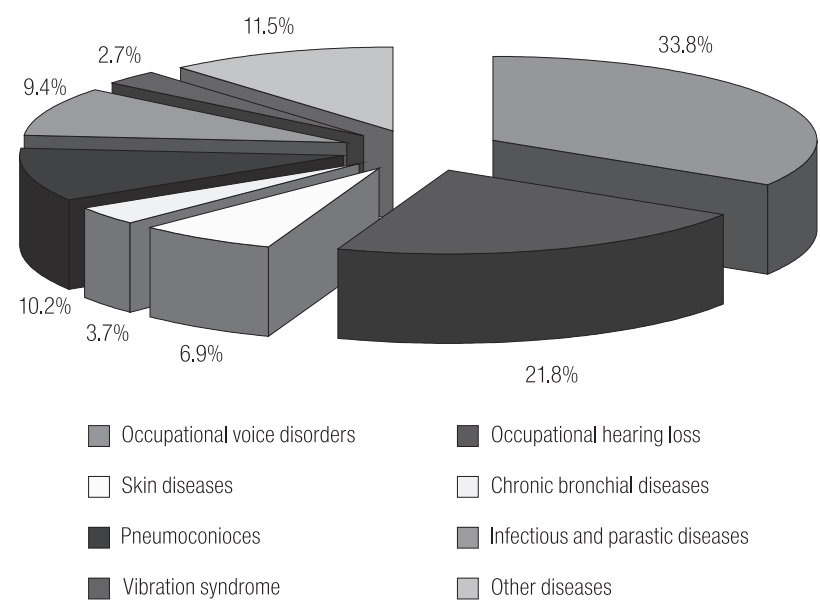

Occupational voice disorders were the most frequently certified category of occupational diseases, making up about $34 \%$ of all cases.

Fig. 2. Occupational voice disorders in Poland in 2000

analysis [36]. The most common tool is laryngovideostroboscopy. A comparison of successive larynx imaging archived over the years contributes a lot of valuable information in the diagnosing and certifying of occupational voice disorders.

Occupational voice disorders have been included in the list of occupational diseases according to the legal regulations in Poland since 1974. Recently, the following laryngeal lesions have been recognized as profession-related voice disorders [2] and are the basis for claiming financial compensation:

1. Irreversible vocal nodules (Photo 1, Movie 1).

2. Hypertrophy of the vocal folds (secondary to vocal effort) (Photo 2, Movie 2).

3. Asthenia of the internal larynx muscles, which contributes to irreversible glottal insufficiency (spindle-shaped glottal closure) and to permanent dysphonia (Photo 3, Movie 3). Ad 1. Vocal nodules are certified as an occupational disease if they are permanent and irreversible. In Poland, we determine them as hard vocal nodules in contrast to the reversible, the so-called soft vocal nodules (prenodules). Moreover, in female teachers at an older age, who have been suffering from vocal nodules for a long time, phoniatricians have frequently observed polypoid 

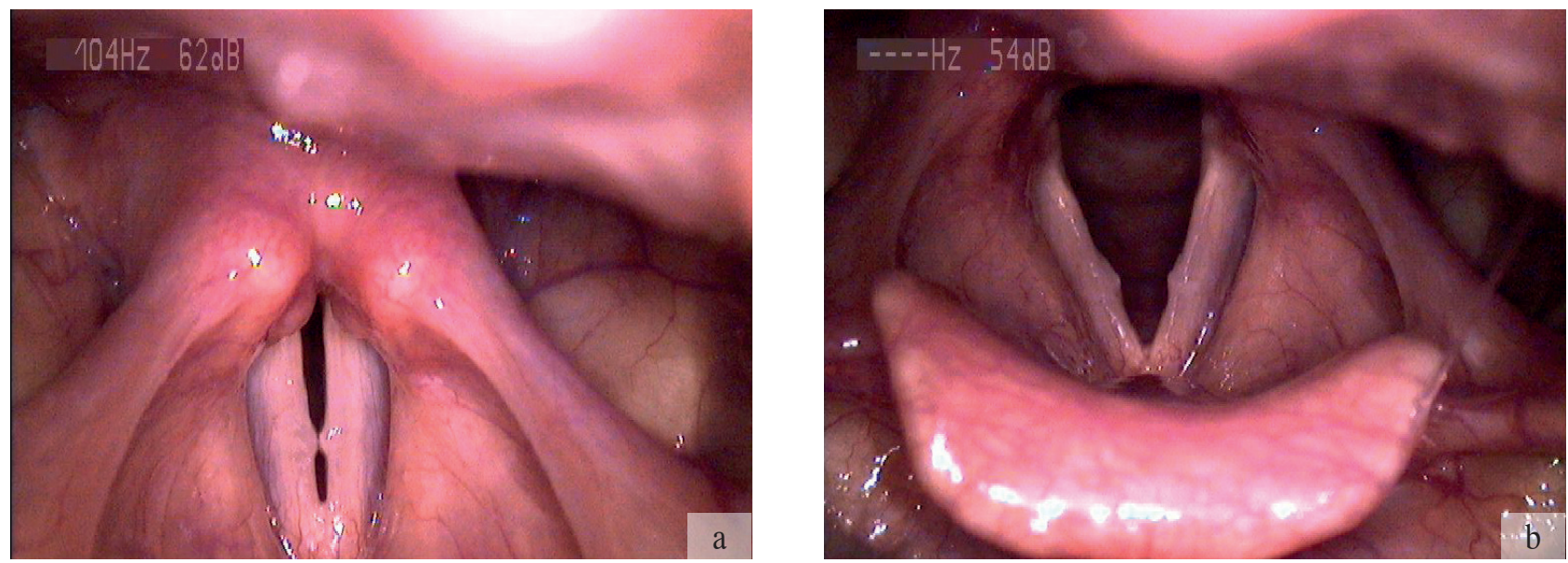

a) Image of the larynx during phonation

b) Image of the larynx during breathing

Photo 1. Vocal nodules - see Movie 1
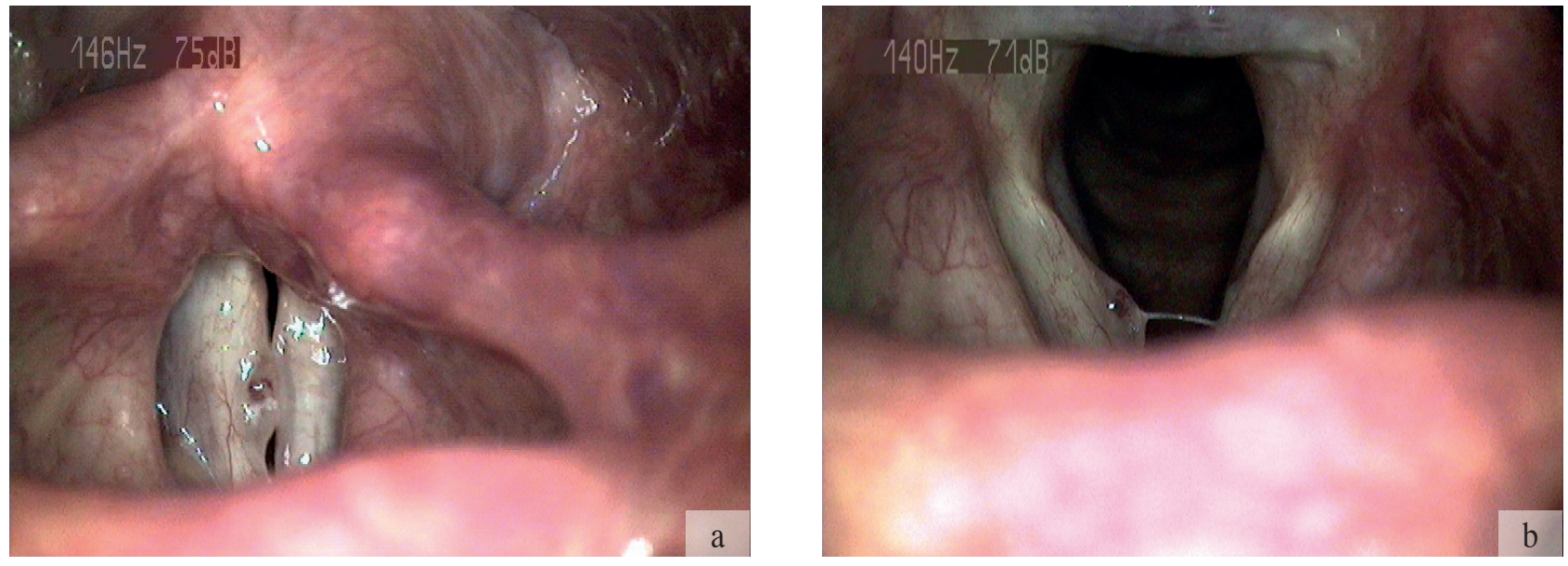

Abbreviations as in Photo 1.

Photo 2. Hypertrophy of the vocal folds (secondary to vocal effort) - see Movie 2

hypertrophy of those lesions, like the ones presented in the figure (Photo 4, Movie 4).

Ad 2. The vocal fold hypertrophy caused by vocal overload frequently manifests itself as benign vocal fold masses, mainly polypoid or fibrovascular changes, localized on the edges of the vocal folds. They are a consequence of repeated movements and collisions of the vocal folds during hyperphonation. The lesions start mainly from the middle one third of the entire vocal fold or at the junction of the anterior one third and posterior two thirds. These pathologies are frequently unilateral at first, but with the progress of the disease the contralateral fold can become affected too. Occupation-related vocal fold hypertrophy should be differentiated from Reinke's edema - major edematose-polypoid changes which are causally associated with cigarette smoking.

Ad 3. Asthenia of the internal larynx muscles is defined as "paresis" of the internal larynx muscles. This term describes 

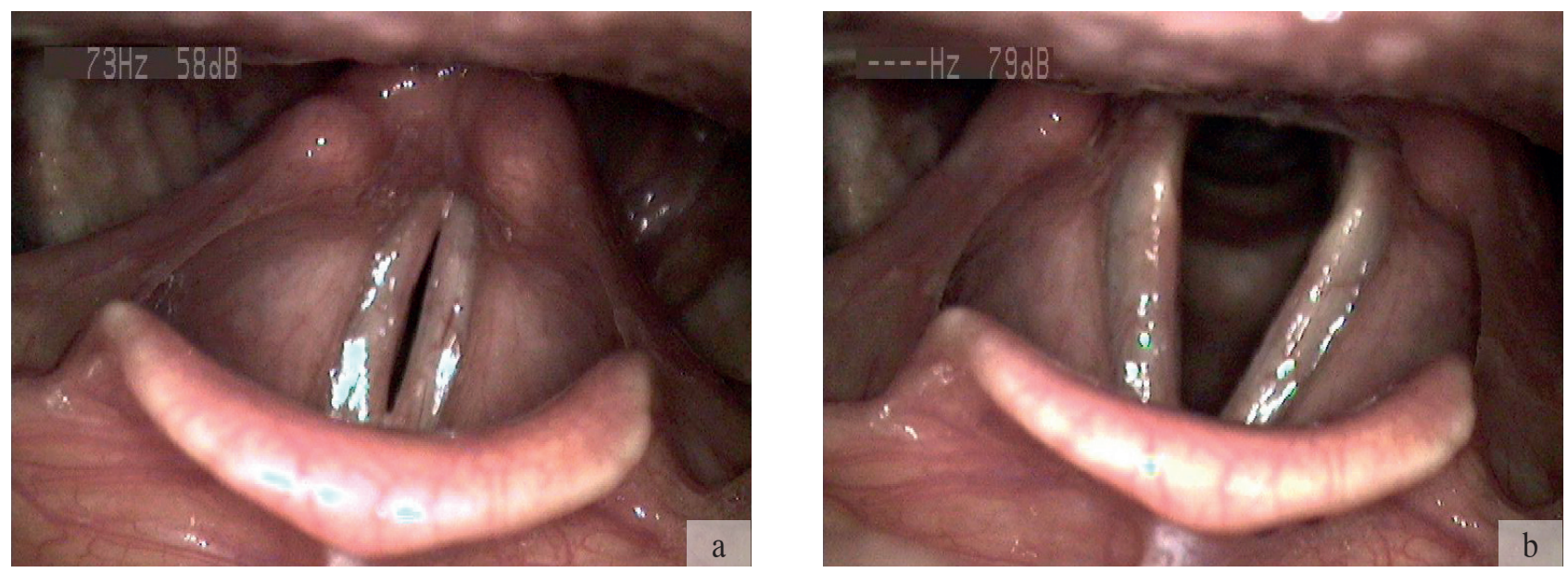

Abbreviations as in Photo 1.

Photo 3. Asthenia of the internal larynx muscles, which contributes to irreversible glottal insufficiency (spindle-shaped glottal closure) and to permanent dysphonia - see Movie 3
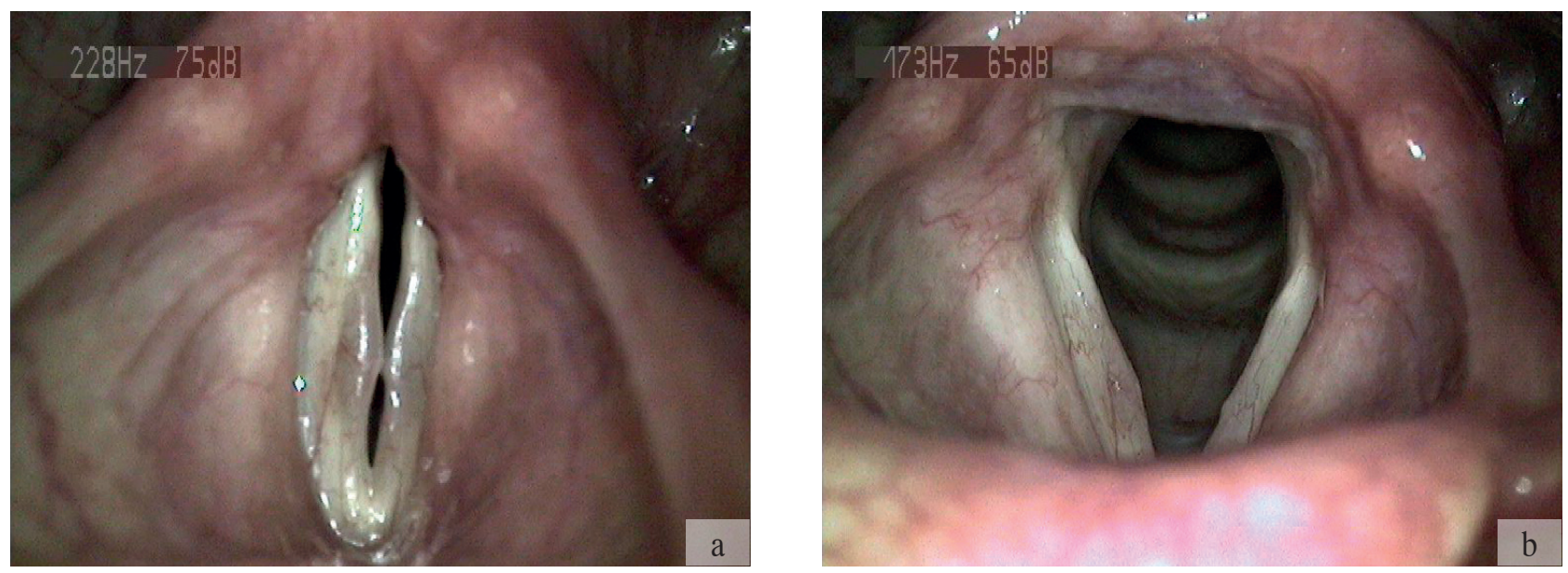

Abbreviations as in Photo 1.

Photo 4. Polypoid degeneration of vocal nodules in female teachers at an older age - see Movie 4

irreversible asthenia/atrophy of the internal larynx muscles causing glottal insufficiency (mainly spindle-shaped) and permanent dysphonia. These voice disorders are related to long-lasting vocal fatigue which can cause glottal hypotonia (e.g. after voice overload). This frequently turns into asthenia due to the loss of muscular tonus in the vocal muscles. Its characteristic features are the bowed shape of the vocal fold edges and the lack of glottal closure in the inter-membranaceous part of the glottis. This disease entity could be recognized after about 2 years of observation of the disorder's trend during phoniatric treatment.

Although in Poland phoniatricians have been trying to come up with the most accurate description of those voice disorders, the authors realize that it still needs to be made more precise.

The prerequisite for the certification of occupational voice disorders is the case of excessive voice loading, which is defined for teachers as full-time employment (minimum $18 \mathrm{~h}$ 
per week in Poland) for at least 15 years. For other professions, excessive vocal effort has not been established yet. The main specialist in charge of certifying occupational diseases is an occupational medicine physician, whose role is to determine a causal relationship between the voice disorders and work conditions, esp. exposure to harmful factors, such as excessive vocal load, e.g. in noise. An important aspect of the certification procedure is the assessment of the voice function performed by an otolaryngologist or a phoniatrician, whose role is also to recognize traits of occupational voice disorders if they exist and to monitor the dynamics of changes during the period of treatment.

The most frequently certified occupational voice disorders in Poland include asthenia of the internal larynx muscles with glottal insufficiency (64\% of all cases), followed by hypertrophy of the vocal folds (23\%), and vocal nodules (5\%) [35]. Figure 3 presents detailed information concerning the different types of clinical subgroups of occupational voice disorders certified in the last decade.

The above observation could be explainable by the fact that a tendency to develop vocal nodules is observed in young female teachers with a short employment history. These data are consistent with the figures from studies from other countries [37], which have reported that nodules occur frequently during the first years of teaching. Moreover, if the treatment of young teachers suffering from vocal nodules fails, they frequently change their profession.

Occupational voice disorders in Poland are most frequently certified among women (86\% of all cases) with a long period of teaching (above 20 years - more than $75 \%$ of all cases) [35]. These Polish data are consistent with the findings of Roy et al. who identified that being a female teacher, aged 40-59, and having more than 16 years of teaching experience were each positively associated with being affected by voice disorders [5].

Unlike in Poland, in other EU countries the impact of occupational dysphonia is undervalued and occupational voice disorders are not included in the list of occupational

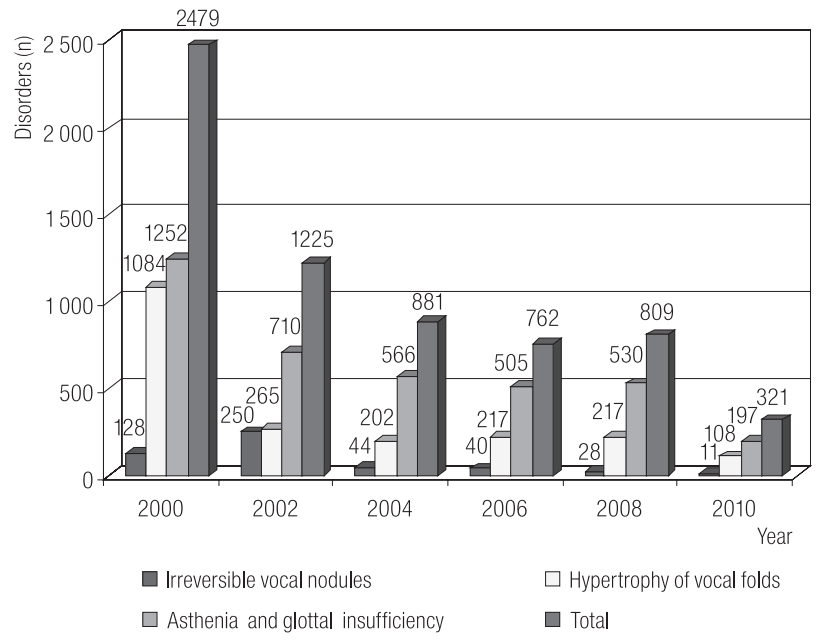

Fig. 3. Occupational voice disorders in Poland in the years 2000-2010: by diagnoses and the total

diseases. It can be explained by the lack of this disease entity in the basic list of occupational diseases specified in the EU Commission Recommendation 2003/670/ EC. However, in Annex I to the "European Schedule" in point 2.503 , there are only listed nodules on the vocal cords caused by sustained work-related vocal effort [38]. In Poland, in the case of a certified occupational voice disorder, the person may receive a single financial indemnity (calculated proportionally to the percentage of the loss of health). According to the obligatory regulations, the percentage of health detriment resulting from occupational voice disorders may range between $10 \%$ and $40 \%$ [39], but in practice it is 10-20\%. If, in the next step of the procedure, partial work disability due to occupational disease is confirmed, the claimant may receive a pension too. However, at present, because of the budget cuts, the pension is granted for 1-2 years only and the person is expected to retrain in order to get another job.

\section{PROPHYLAXIS}

An important role of prevention of occupational voice disorders has been recognized in Poland for many years. It has been introducing better health arrangements for 
voice professionals in the last decades. According to the obligatory regulations, all teachers employed in public schools in Poland are examined by laryngologists before they start work, and then the examination is repeated every 5 years [40]. If a laryngologist diagnoses the impaired glottal function in a teacher, the patient is referred to a phoniatric outpatient clinic.

Since the late 1990s, in Poland, the Nofer Institute of Occupational Medicine has been running a series of national programs, financed by the Ministry of Health, which focus on the prevention of occupational voice disorders in teachers. These programs resulted in formulating the principles for vocal training provided to teachers and to students of teacher-training colleges. In 2006, a new, optional, subject was introduced into the syllabus of teachertraining colleges - Vocal Hygiene and Techniques of Correct Voicing (30 h).

The prophylactic programs resulted also in developing a model of extensive treatment of voice disorders, which involves collaboration between occupational medicine doctors, laryngologists, phoniatricians, and speech pathologists. This model was implemented in the regional centers of occupational medicine all over Poland. Several of them have been providing prevention programs for teachers ever since, focusing on voice hygiene education and vocal training. Initially, the programs were addressed mainly to younger teaching staff, but at the moment, at a request coming from other teachers, there is no age limit, and the program is available for every full-time active teacher. It has been observed that the effectiveness of these programs does not depend on the age of the teachers, but on their motivation. A multi-center study has proven that vocal training is a crucial method of voice therapy [41]. It can significantly improve the "voice fitness for duty". This could be associated with an acquired ability to compensate for vocal loading. Another study indicates that vocal training may bring about an improvement in voice stability, which enhances the endurance of the vocal apparatus [28].
The last program has been addressed to teachers with a long period of teaching experience, who suffer from severe chronic voice disorders. Some studies have proven that this group of teachers has reacted more strongly to vocal loading factors than their voice-healthy colleagues [42]. They are more often absent from work because of voice problems. Thus, this program aimed at improving their vocal capacity and enabling them to continue working in their profession. The coping strategies concerning occupational stress and burnout symptoms were also taken into account. A result of the program was formulating and implementing a multi-specialist model of extensive treatment of voice disorders both in an outpatient clinic and in a health spa. The model includes holistic management of occupational dysphonia with a close collaboration of phoniatricians, speech therapists, psychologists, and physiotherapists/osteopaths [43]. Besides, in Poland, each teacher throughout their professional career is eligible to take three one-year-long paid leaves to take care of, or regain, health. Such a period may be used for voice therapy which is often combined with a stay and an extensive treatment in health spas.

\section{CONCLUSION}

To conclude, despite the evident decrease in the number of newly registered occupational voice disorders cases in Poland, the issue still remains valid. The early diagnosis of occupational dysphonia improves the outcomes of treatment and optimizes the methods of prophylaxis. This is of special significance if one of the important factors in the pathogenesis of occupational dysphonia turns out to be incorrect voicing, which brings about pathological compensation in vocal overload. The management of occupational voice disorders should be multidisciplinary and ought to involve perfect collaboration between laryngologists, phoniatricians, and speech pathologists, as well as occupational medicine doctors. 


\section{REFERENCES}

1. Carding P. Occupational voice disorders: Is there a firm case for industrial injuries disablement benefit? Logop Phoniatr Vocol. 2007;32:47-8, http://dx.doi. org/10.1080/14015430600881901.

2. [Ordinance of the Council of Ministers of 30 Jun 2009 on occupational diseases. The Official Journal of the Poland 2009, no. 105, pos. 869]. Polish.

3. Verdolini K, Ramig LO. Occupational risks for voice problems. Logop Phoniatr Vocol. 2001;26:37-46, http://dx.doi. org/0.1080/14015430119969.

4. Titze IR, Lemke J, Montequin D. Populations in the U.S. workforce who rely on voice as primary tool of trade: A preliminary report. J Voice. 1997;11(3):254-9, http://dx.doi. org/10.1016/S0892-1997(97)80002-1.

5. Roy N, Merrill RM, Thibeault S, Parsa R, Gray SD, Smith EM. Prevalence of voice disorders in teachers and general population. J Speech Lang Hear Res. 2004;47: 28193, http://dx.doi.org/0.1044/1092-4388(2004/023).

6. Śliwinska-Kowalska M, Niebudek-Bogusz E, Fiszer M, Kotyło P, Ziatkowska E, Stępowska M, et al. The prevalence and risk factors for occupational voice disorders in teachers. Folia Phoniatr Logop. 2006;58:85-101, http://dx.doi. org/10.1159/000089610.

7. Central Statistical Office. [Statistical Yearbook of Poland]. Warszawa: Office; 2005. Polish.

8. De Jong F. An introduction to the teacher's voice in a biopsychosocial perspective. Folia Phoniatr Logop. 2010;62: 5-8, http://dx.doi.org/10.1159/000239058.

9. Ziegler A, Gillespie AI, Verdolini Abbott K. Behavioral treatment of voice disorders in teachers. Folia Phoniatr Logop. 2010;62:9-23, http://dx.doi.org/10.1159/000239059.

10. Hodgson M. Rating, ranking and understanding acoustical quality in university classrooms. J Acoust Soc Am. 2002;112(2):568-75, http://dx.doi. org/10.1121/1.1490363.

11. Jonsdottir V, Laukkanen AM, Vilkman E. Changes in teachers' speech during a working day, with and without electric sound amplification. Folia Phoniatr Logop. 2002;54(6): 282-7, http://dx.doi.org/10.1159/000066149.

12. Dejonckere PH. Occupational voice-care and cure. The Hague: Kugler Publications; 2001.

13. Geneid A, Ronkko M, Airaksinen L, Voutilainen R, Toskala E, Alku P, et al. Pilot study on acute voice and throat symptoms related to exposure to organic dust: preliminary findings from a provocation test. Logop Phoniatr Vocol. 2009;34(2): 62-72, http://dx.doi.org/10.1080/14015430902845711.

14. Mesquita de Medeiros A, Baretto SM, Assuncao AA. Voice disorders (dysphonia) in public school female teachers working in Belo Horizonte: prevalence and associated factors. J Voice. 2008;22(6):676-87, http://dx.doi.org/10.1016/ j.jvoice.2007.03.008.

15. Bermudez de Alvear R, Martinez-Arquero G, Baron J, Hernandez-Mendo A. An interdisciplinary approach to teachers' voice disorders and psychosocial working conditions. Folia Phoniatr Logop. 2010;62:24-34, http://dx.doi. org $/ 10.1159 / 000239060$.

16. O’ Hara J, Miller T, Carding P, Wilson J, Deary V. Relationship between fatigue, perfectionism and functional dysphonia. Otolaryngol Head Neck Surg. 2011;144(6):921-6, http:// dx.doi.org/10.1177/0194599811401236.

17. Van Wijck-Warnaar A, Van Opstal MJMC, Exelmans K, Schaekers K, Thomas G, de Jong FICRS. Biopsychosocial impact of voicing and general coping style in teachers. Folia Phoniatr Logop. 2010;62:40-6, http://dx.doi.org/ 10.1159/000239062.

18. Koufman JA. Laryngeal muscle tension patterns (MTPs). In: Rubin JS, Sataloff RT, Korovin GS, editors. Diagnosis and Treatment of Voice Disorders. New York: Thomson Delmar Learning; 2003. p. 175-82.

19. Maniecka-Aleksandrowicz B, Domeracka-Kołodziej A. Medical Aspects of Teachers' Voice Production. In: Przybysz-Piwkowa M, editor. A Teacher's Voice Production. Selected Aspects. Warszawa: COKN 2006.

20. Obrębowski A. [Voice organ and its significance in social communication]. Poznań: Medical University of Poznań; 2008. Polish. 
21. Belafsky PC, Postma GN, Reulbach TR, Holland BW, Koufman JA. Muscle tension dysphonia as a sign of underlying glottal insufficiency. Otolaryngol Head Neck Surg. 2002;127(5):448-51, http://dx.doi.org/10.1067/ mhn.2002.128894.

22. Boucher VJ, Ayad T. Physiological attributes of vocal fatigue and their acoustic effects: A synthesis of findings for a criterion-based prevention of acquired voice disorders. J Voice. 2010;24(3):324-36, http://dx.doi.org/10.1016/ j.jvoice.2008.10.001.

23. Hunter EJ, Titze IR. Quantifying vocal fatigue recovery: dynamic vocal recovery trajectories after a vocal loading exercise. Ann Otol Rhinol Laryngol. 2009;118(6):449-60.

24. Remacle A, Finc C, Roche A, Morsomme D. Vocal impact of a prolonged reading task at two intensity levels: objective measurements and subjective self-ratings. J Voice. 2012;26(4):177-86, http://dx.doi.org/10.1016/ j.jvoice.2011.07.016.

25. Vilkman E. Occupational safety and health aspects of voice and speech professions. Folia Phoniatr Logop. 2004;56(4):220-53, http://dx.doi.org/10.1159/000078344.

26. Niebudek-Bogusz E, Fiszer M, Kotyło P, ŚliwińskaKowalska M. Diagnostic value of voice analysis in assessment of occupational voice pathologies in teachers. Logop Phoniatr Vocol. 2006;31:100-6, http://dx.doi. org/10.1080/14015430500295756.

27. Remacle A, Morsomme D, Berrué E, Finck C. Vocal impact of a prolonged reading task in dysphonic versus normophonic female teachers. J Voice. 2012;26(6):820-33, http:// dx.doi.org/10.1016/j.jvoice.2012.06.002.

28. Niebudek-Bogusz E, Kotyło P, Politański P, ŚliwińskaKowalska M. Acoustic analysis with vocal loading test in occupational voice disorders: outcomes before and after voice therapy. Int J Occup Med Environ Health. 2008;21(4): 3018, http://dx.doi.org/10.2478/v10001-008-0033-9.

29. KayPentax. Products. [cited 2012 Oct 7]. Available from: http:// www.kayelemetrics.com/index.php?option $=$ com_product $\&$ view= product\&Itemid $=3$.
30. Sonvox.Voxlog [cited 2012 Oct 7]. Available from: http:// www.sonvox.com/voxlog.

31. World Health Organization. International classification of impairments, disabilities and handicaps:a manual of classification, relating to the consequences of disease. Geneva: World Health Organization; 1980. p. 25-43.

32. Pruszewicz A, Obrębowski A, Wiskirska-Woźnica B, Wojnowski W. [Complex voice assessment - Polish version of the Voice Handicap Index (VHI)]. Otolaryngol Pol. 2004;58:547-9. Polish.

33. Verdonck-de Leeuw I, Kuik DJ, De Bodt MS, Guimaraes I, Holmberg EB, Nawka T, et al. Validation of the Voice Handicap Index (VHI) by assessing equivalence of European translations. 7th Pan European Voice Conference; August 29th September 1st 2007; Groningen, Netherlands. Groningen; 2007.

34. Laukkanen AM, Järvinen K, Artkoski M, Waaramaa-MäkiKulmala T, Kankare E, Sippola S, et al. Changes in voice and subjective sensations during a 45-min. vocal loading test in female subjects with vocal training. Folia Phoniatr Logop. 2004;56:335-46, http://dx.doi.org/10.1159/000081081.

35. Szeszenia-Dąbrowska N, Wilczyńska U, Szymczak W, Pepłońska B. [Occupational diseases in Poland in 2010]. Łódź: Nofer Institute of Occupational Medicine; 2011. Polish.

36. Rubin JS, Sataloff RT, Korovin GS, editors. Diagnosis and treatment of voice disorders. New York: Thomson Delmar Learning; 2003.

37. Perez Fernandez CA, Lopez PJ. Vocal folds nodules. Risk factors in teachers. A case control study design. Acta Otorrinolaringol Esp. 2003;54(4):253-60.

38. Council Directive: 2003/670/CE. Brussels: European Economic Community; 2003 [cited 2012 Oct 7]. Available from: http://europa.eu/legislation_summaries/employment_ and_social_policy/health_hygiene_safety_at_work/c11112_ en.htm.

39. [Ordinance of the Minister of Labour and Social Policy of 28 February 2012 M.P]. The Official Journal of the Poland 2012, no. 0, pos. 127. Polish. 
40. [Ordinance of the Minister of Health of 18 May 1996]. The Official Journal of the Poland 1996, no. 69, pos. 332. Polish.

41. Niebudek-Bogusz E, Sznurowska-Przygocka B, Fiszer M, Kotyło P, Sinkiewicz A, Modrzewska M, et al. The effectiveness of voice therapy for teachers with dysphonia. Folia Phoniatr Logop. 2008;60(3):134-41, http://dx.doi. org/10.1159/000120290.

42. Tavares E, Martins R. Vocal evaluation in teachers with or without symptoms. J Voice. 2007;21(4):407-14, http://dx. doi.org/10.1016/j.jvoice.2006.04.001.
43. Marszałek S, Niebudek-Bogusz E, Woźnicka E, Malińska J, Golusiński W, Śliwińska-Kowalska M. Assessment of the influence of osteopathic myofascial techniques on normalization of the vocal tract functions in patients with occupational dysphonia. Int J Occup Med Environ Health. 2012;25(3): 225-35, http://dx.doi.org/10.2478/S13382-012-0041-7.

This work is available in Open Access model and licensed under a Creative Commons Attribution-NonCommercial 3.0 Poland License - http://creativecommons.org/ licenses/by-nc/3.0/pl/deed.en. 